\title{
KAMIQUASE E O PALIMPSESTO: AS RELAÇÕES DE TRANSTEXTUALIDADE E METALINGUAGEM EM PAULO LEMINSKI
}

\author{
KAMIQUASE AND THE PALIMPSEST: THE \\ TRANSTEXTUALITY AND METALANGUAGE RELATIONS \\ IN PAULO LEMINSKI
}

Carlos Ossanes ${ }^{26}$

Resumo: Tendo por base os trabalhos de Gerard Genette, a respeito dos fatores de transtextualidade abordados em Palimspestos, este artigo propõese a analisar a poesia do curitibano Paulo Leminski, a partir de um recorte de poemas que apresentem correlações com outras obras e autores. Ainda, na seleção de versos que compõem o escopo desse trabalho, buscou-se priorizar aquelas que apresentassem conteúdo remetendo à sua própria construção (metalinguagem). Por fim, observou-se, a partir da análise dos seis livros presentes na edição Toda Poesia (2013), que a estética do poeta Paulo Leminski manifesta ambas as marcas, sendo recorrente tema de sua criação poética.

Palavras-chave: Transtextualidade; Metalinguagem; Leminski; Toda Poesia.

Abstract: Based on the work of Gerard Genette, regarding transtextuality factors discussed in Palimpsests, this article proposes to analyze the poetry of Paulo Leminski from a clipping poems that have correlations with other works and authors. By this bias, the selection of verses that make up the scope of this work soughts to prioritize those who submit content referring to its own building (metalanguage). Finally, it was observed from the analysis of the six edition books present in Toda Poesia (2013), the aesthetic of Paul Leminski poet expresses both brands, being recurring theme of his poetic creation.

Key words: Transtextuality; Metalanguage; Leminski; Toda Poesia.

${ }^{26}$ Mestrando em Estudos da Literatura pelo Programa de Pós-Graduação em Letras da Universidade Federal do Rio Grande do Sul (UFRGS). Bolsista CAPES. carlosossanes@yahoo.com.br. 


\section{Entre caprichos e relaxos}

O presente artigo visa articular uma análise interpretativa, seguida de comentário, a um recorte da poesia de Paulo Leminski, definida a partir de uma triagem que levou em consideração: (a) a presença de hipertextos de autores e obras precedentes, (b) sempre que possivel, a construção do seu corpus sendo o conteúdo do próprio poema (metalinguagem) e (c) a amostragem que contemplasse todos os seis livros encontrados na edição Toda Poesia (2013). Assim, foram selecionados nove poemas, atendendo à exigência de conter no mínimo um exemplar dos seis livros, demonstrando a presença de hipertextos com outros títulos e nomes. A poesia do samurai malandro (alcunha para Paulo Leminski, nas palavras de Dinarte Albuquerque) demonstra a intersecção entre o rigor técnico estruturalista e o fluxo contínuo de ideias da geração marginal. Sua marca estética fica evidente no título caprichos e relaxos, dentro da idiossincrasia presente no nome: como pode algo caprichado ter traços de relaxamento? Justamente nessa binaridade Leminski constrói sua poesia, entre o conteúdo refinado e de caráter crítico, atrelado à subjetividade exacerbada, presente nos versos soltos e sem compromisso com a estética tradicional.

Pretende-se, como método desse trabalho, fazer algumas ponderações sobre a teoria da transtextualidade de Gerard Genette, a fim de se iluminar o caminho de análise dos poemas de Leminski. Proposto em Palimspestos: a literatura de segunda mão, o conceito de transtextualidade (anteriormente tratado pelo autor como paratextualidade) remete ao dialogismo bakhtiniano, referindo-se a esses infinitos contatos que os textos podem provocar. Nas palavras de Robert Stam (2007), essa "doença textualmente transmissivel" revela que todo texto esconde, por trás de si, implícita ou explicitamente, outra gama de textos. O palimpsesto, assim ilustrado no título de Genette, faz alusão ao tipo de pergaminho do qual eram apagadas as inscrições mais antigas, a fim de se escreverem novas. Ainda que não sejam visíveis em um 
olhar desatento, as escrituras mais antigas mantêm-se vivas por trás da superfície de escrita mais forte. Metaforicamente, todo texto traz dentro (ou por trás) de si uma infinidade de outros textos com o qual o autor teve contato, seja por leitura ou por intermédio da sua imersão na sua cultura e na sua tradição.

Cinco são os fatores elencados por Genette como de transtextualidade, sendo eles: (a) a intertextualidade, a presença física de um texto (ou mais) em outro, por citação, plágio ou alusão; (b) a paratextualidade, referências naquilo que está além do texto, de forma mais distante; (c) a metatextualidade, rememoramento crítico de um texto; e, provavelmente mais importante forma das cinco, (d) a hipertextualidade. Genette entende por hipertextualidade

toda relação que une um texto $B$ (que chamarei hipertexto) a um texto anterior $\mathrm{A}$ (que, naturalmente, chamarei hipotexto) do qual ele brota, de uma forma que não é a do comentário. Como se vê na metáfora - brota - e no uso da negativa, esta definição é bastante provisória. Dizendo de outra forma, consideremos uma noção geral de texto de segunda mão [...] ou texto derivado de outro texto preexistente (GENETTE, 2006, p. 12-13).

Dessa forma, ao se fazer a leitura dos poemas escolhidos de Leminski, tratar-se-á de dar atenção à procura dos hipertextos, elucidando - sempre que possível - o provável referente com o qual dialoga.

Ao se analizar os hipertextos de uma obra literária, é fundamental ter em mente que esse objeto referenciado (hipotexto) não deve ser visto como original, igualmente. Da mesma forma, pode haver casos em que a hipertextualidade seja tão diluída a ponto de o hipotexto ser um conceito, uma obra ou até mesmo um outro hipertexto. É maduro, também, perceber que esses hipertextos podem ser lidos sem que se conheça o referente, uma vez que comportam 
[...] uma significação autônoma e, portanto, de uma certa maneira, suficiente. Mas suficiente não significa exaustiva. Há em todo hipertexto uma ambigüidade que Riffaterre recusa à leitura intertextual, que ele preferiu definir como um efeito de "silepse". Essa ambigüidade se deve precisamente ao fato de que um hipertexto pode ao mesmo tempo ser lido por si mesmo, e na sua relação com seu hipotexto (GENETTE, 2006, p. 44).

Adentrando, adiante, na análise e interpretação do recorte de versos de Paulo Leminski, tratar-se-á de atender aos objetivos e, também, evidenciar o caráter transtextual (apontando hipertextos) e metalinguístico (demonstrando sua face auto-descritiva), divididos, os versos, entre os seis livros que compõem Toda Poesia: quarenta clics em curitiba (1976), caprichos $\mathcal{E}$ relaxos (1983), distraidos venceremos (1987), la vie en close (1991), o ex-estranho (1996) e winterverno (2001).

\title{
quarenta clics em curitiba [1976]
}

O projeto quarenta clics em curitiba originou-se da mistura entre a proposta fotográfica de Jack Pires, que registrava a cidade de Curitiba (Paraná) há algum tempo na época, com uma série de poemas do Leminski. O resultado desse trabalho foi uma espécie de mapa, que também ilustra metaforicamente o primeiro poema recortado para o corpus de análise desse artigo:

\author{
Quem me dera \\ um mapa de tesouro \\ que me leve a um velho baú \\ cheio de mapas do tesouro
}

A ideia do palimpsesto nos remete diretamente ao velho baú cheio de mapas do tesouro. Nesse processo, (a leitura de) um livro refere-se a esse mapa do tesouro que leva o leitor a outros mapas infinitos, em uma cadeia gradativa de hipertextos levando o 
indivíduo a seus hipotextos. Pode-se, também, dessa forma, entender que o poema faz alusão ao próprio processo da escrita e da leitura, se não desses versos, de outros do próprio autor, deixando possivel a visibilidade da metalinguagem na criação do poema.

\section{caprichos \& relaxos [1983]}

Capricho e relaxo parecem palavras opostas. Na poesia de Paulo Leminski, ambas acabam por caracterizar perfeitamente o tipo de estética e conteúdo apresentados pelo curitibano. No poema que segue, pode-se observar alguns aspectos interessantes da internalização da cultura na poesia do autor:

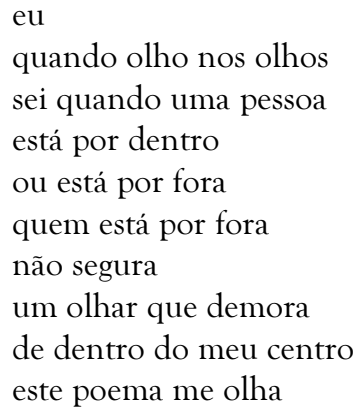

Ao dizer que "de dentro do meu centro \este poema me olha", a poesia assume o caráter metalinguístico de tratar do próprio ato criativo, deixando entender que trata sobre si mesmo (ou, em outra interpretação, que o poema está pronto e o encarando). De qualquer forma, assumir os olhos como espelhos da alma é um conceito que já se mostra popular, de forma a demonstrar transtextualidade com o conhecimento empírico popular; olhar nos olhos para passar confiança ou, ainda, para proporcionar uma conexão transcendental. 


\title{
distraídos venceremos [1987]
}

Esse projeto literário é, provavelmente, o que mais retrata a face metalinguística de Leminski. Em seus três capítulos (distraidos venceremos, ais ou menos e kawa cauim), o poeta escreve sobre temáticas da natureza e do tempo, principalmente ao destacar, no último capítulo, uma série de haicais, ainda que com uma releitura formal da estética japonesa (uma estrofe com três versos contendo, em ordem, 5, 7 e 5 sílabas). O primeiro poema recortado para o escopo desse trabalho é despropósito geral:

\author{
Esse estranho hábito, \\ escrever obras-primas, \\ não me veio rápido. \\ Custou-me rimas. \\ Umas, paguei caro, \\ liras, vidas, preços máximos. \\ Umas, foi fácil. \\ Outras, nem falo. \\ Me lembro duma \\ que desfiz a socos. \\ Duas, em suma. \\ Bati mais um pouco. \\ Esse estranho abuso, \\ adquiri, faz séculos. \\ Aos outros, as músicas. \\ $\mathrm{Eu}$, senhor, sou todo ecos.
}

A metalinguagem é evidente, ao se ler a ideia de histórico da escrita dos poemas, evidente em "me lembro duma [rima] que desfiz a socos". O processo de hipertextualização é destacado nos excertos "adquiri, faz séculos" e "Eu, senhor, sou todo ecos". O ritmo nesse poema alude à frequência sonora do próprio eco, reflexo modificado (mas não necessariamente destorcido) das vozes que resultaram nesse poema. É interessante para esse momento da análise que o poema, entender um pouco mais sobre as conexões 
entre os versos de uma estrutura poética. Ao se fazer a leitura de um poema, o que primeiramente nos chama a atenção

não são as sonoridades específicas dos fonemas, que só aparecem quando de certo modo destruímos o verso pela análise fonética. O que aparece é o movimento ondulatório que caracteriza o verso e o distingue de outro: este movimento é o ritmo (CANDIDO, 1996, p. 43).

Pelas palavras de Antonio Candido, é nesse movimento da troca de sons entre versos - que acabam por ritmar o poema, ainda que o ritmo não dependa da rima - que nasce o ritmo do poema. Ainda que houvesse certo ritmo nos versos anteriormente destacados da poesia do Leminski, cabe ressaltar que nesse o processo se mostrou ainda mais evidente, como em lesse esTRAnho hábito \escreVER obras-primas \não me VEIO rápido\ cusTOU-me rimas.

Outro poema que apresenta o mesmo processo, em relação à metalinguagem e à transtextualização, é desencontrários:
Mandei a palavra rimar, ela não me obedeceu.
Falou em mar, em céu, em rosa, em grego, em silêncio, em prosa.
Parecia fora de si, a sílaba silenciosa.
Mandei a frase sonhar, e ela se foi num labirinto.
Fazer poesia, eu sinto, apenas isso.
Dar ordens a um exército, para conquistar um império extinto

Ao começar a estrofe com o verso "mandei a palavra rimar", Leminski já aponta para (se não a construção de toda sua poesia, ao menos) a construção desse próprio poema. Ao pretender "Dar ordens a um exército, \para conquistar um império extinto.”, percebe-se a transtextualidade no momento ao observar o interesse 
em, ao escrever, em retomar uma tradição já ultrapassada (aqui, sem juizo de valor, apenas referindo-se a algo precedente).

\section{la vie en close [1991]}

Publicados postumamente por Alice Ruiz (sua companheira), la vie en close faz um intertexto, já no título, com a música de Edith Piaf, La vie en rose (A vida cor-de-rosa). No poema a seguir, pode-se fazer algumas ponderações interessantes sobre a intertextualidade, mais diretamente, e o movimento de construção se auto-mencionando:

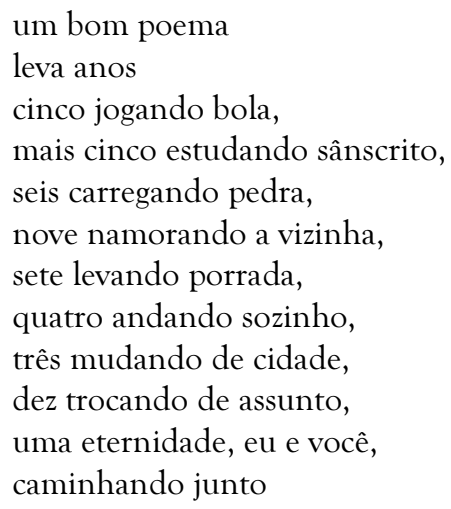

Ao dizer que "um bom poema\leva anos", Leminski demonstra os dois fatores citados anteriormente, pois recorta o processo de criação da poesia e, também, a relevância da tradição na construção desses versos. Há também esse reforço em "cinco estudando sânscrito" (alusão a línguas antigas, ao que precede) e ao que está por vir, como se ele, ao escrever, também se tornasse tradição: "uma eternidade, eu e você".

Destaca-se, também, como outro conteúdo recorrente da poesia de Leminski, o trabalho com a etimologia da lingua, assim como o próprio uso da linguística para construir suas formas concretas (como em PERHAPPINESS, presente em caprichos e 
relaxos, que aglutina as palavras perhaps (talvez, em inglês) e happiness (felicidade, em inglês), criando uma nova palavra com sentido literário próprio (a expectativa da felicidade, leitura aqui defendida). A seguir, portanto, o poema ouverture la vie en close:

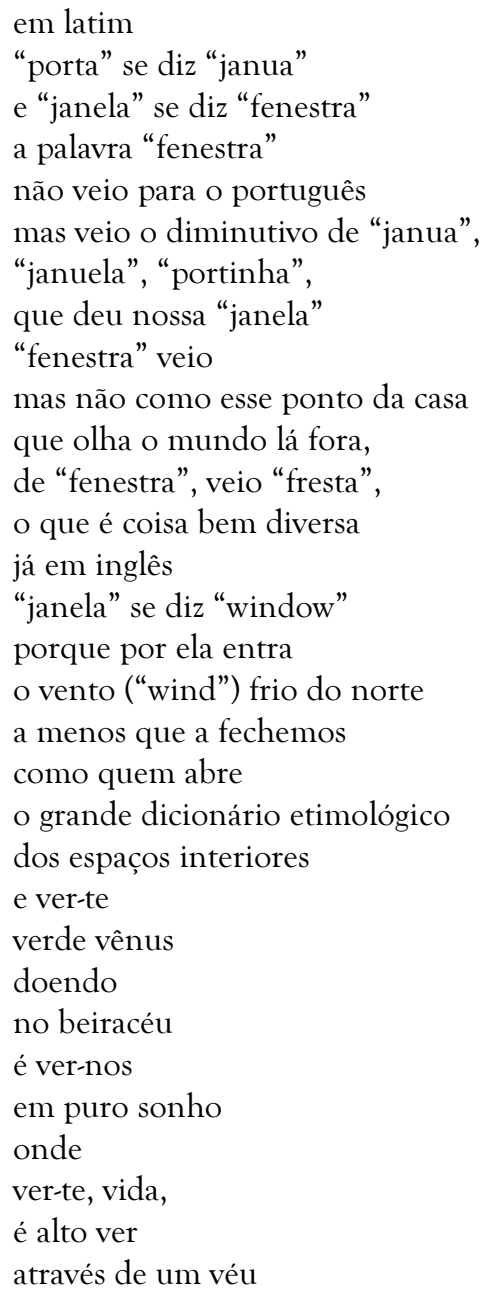


Ao construir sua poesia sobre a etimologia das palavras porta e janela, Leminski expande o conceito linguístico e, até mesmo, a própria conotação das palavras. $\mathrm{O}$ que se cria é uma ideia nova, calcada na subjetividade da leitura do mundo. Ao trabalhar na tradução dessas palavras, criando hipóteses de sua leitura literária, o poeta cria uma nova visão para o imaginário dessas palavras. Esse processo de tradução assemelha-se ao que o Genette acredita ser o mais sensato do trabalho do tradutor: "[...] admitir que ele só pode fazer malfeito, e, no entanto, se esforçar para fazer o melhor possivel, o que significa freqüentemente fazer outra coisa" (GENETTE, 2006, p. 33).

\title{
o ex-estranho [1996]
}

Em sacro lavoro é possivel perceber o peso da tradição (e referências aos milagres e trabalhos de Jesus, como que comparando-os ao do poeta):

\author{
as mãos que escrevem isto \\ um dia iam ser de sacerdote \\ transformando o pão e o vinho forte \\ na carne e sangue de cristo \\ hoje transformam palavras \\ num misto entre o óbvio e o nunca visto \\ O que o amanhã não sabe, \\ o ontem não soube. \\ Nada que não seja o hoje \\ jamais houve
}

\section{Winterverno [2001]}

A aglutinação mencionada em PERHAPINESS mostra-se semelhante no projeto Winterverno. 


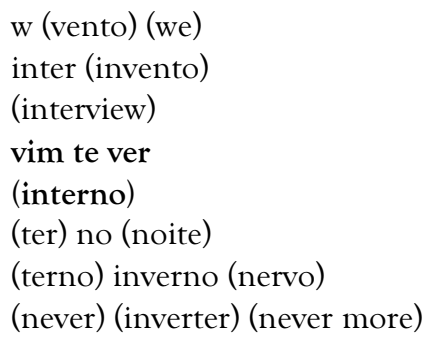

Além do processo de justaposição das palavras, como (ter) no resultar em terno, ou, antes disso, w e inter resultar no posterior inverno (winter, em inglês), pode-se perceber relação, ainda que não necessariamente de seu conteúdo, com $\bigcirc$ Corvo, de Poe, ao mencionar never more.

\section{Um poeta transtextual, uma metapoesia}

A partir do recorte apresentado, pretendeu-se evidenciar o caráter transtextual e metalinguístico da poesia, destacando os elementos em cada um dos versos, apontando para os fatores externos presentes dentro do texto e, também, para o processo de criação estética e de seus conteúdos. Percebeu-se, através desse breve estudo, que a poesia leminskiana evidencia o caráter moderno da arte, de deixar evidente sua face intertextual (como ao evidenciar os autores e obras que relê ou os que visita). $O$ poeta consegue amarrar seus versos de maneira descompromissada com uma escola ou, até mesmo, com um único movimento. Isso destaca, com a quebra de uma estética fixa para revelar outras leituras (dialogismo) dentro do próprio poema, faz de Leminski um interessante exemplo de autor versátil e transtextual. Sua poesia é capaz de resguardar, adentrada sua superfície, inúmeras interpretações (ainda que, nesse trabalho, a proposta não tenha sido a de tecer comentários a respeito delas, apenas apontar os elementos hipertextualizados) que enriquecem o conteúdo de sua poesia, na essência de sua subjetividade. Assim, Toda Poesia é possivelmente um definitivo recorte exemplar de elementos 
transtextualizados e de marcas metalinguísticas, atrelados a uma estética maleável e uma rica crítica social.

\section{Referências e bibliografia consultada}

CANDIDO, A. O estudo analitico do poema. São Paulo: Humanitas Publicações, 1996.

EAGLETON, T. Teoria da Literatura: uma introdução. São Paulo: Martins Fontes, 2003.

ECO, Umberto. Semiótica e filosofia da linguagem. Tradução: M. Fabris e J. L. Fiorin. São Paulo; Ática, 1991.

GENETTE, G. Palimpsestos: a literatura de segunda mão. Tradução de Luciene Guimarães e Maria Antônia Ramos Coutinho. UFMG: Faculdade de Letras, 2005.

LEMINSKI, P. Toda Poesia. São Paulo: Companhia das Letras, 2013.

OURIQUE, J. L. P. [et. al.] Literatura: crítica comparada. Pelotas: Ed. Universitária PREC/UFPEL, 2011.

Recebido em 06 de abril de 2017.

Aprovado em 05 de julho de 2017. 